\title{
European LV microgrid benchmark network: Development and frequency response analysis
}

DOI:

10.1109/ENERGYCON.2018.8398759

Link to publication record in Manchester Research Explorer

\section{Citation for published version (APA):}

Ayaz, M. S. (2018). European LV microgrid benchmark network: Development and frequency response analysis. https://doi.org/10.1109/ENERGYCON.2018.8398759

\section{Citing this paper}

Please note that where the full-text provided on Manchester Research Explorer is the Author Accepted Manuscript or Proof version this may differ from the final Published version. If citing, it is advised that you check and use the publisher's definitive version.

\section{General rights}

Copyright and moral rights for the publications made accessible in the Research Explorer are retained by the authors and/or other copyright owners and it is a condition of accessing publications that users recognise and abide by the legal requirements associated with these rights.

\section{Takedown policy}

If you believe that this document breaches copyright please refer to the University of Manchester's Takedown Procedures [http://man.ac.uk/04Y6Bo] or contact uml.scholarlycommunications@manchester.ac.uk providing relevant details, so we can investigate your claim.

\section{OPEN ACCESS}




\title{
European LV Microgrid Benchmark Network: Development and Frequency Response Analysis
}

\author{
Melike Selcen Ayaz, Rasoul Azizipanah-Abarghooee, Vladimir Terzija \\ The University of Manchester \\ School of Electrical and Electronic Engineering \\ Manchester, UK
}

\begin{abstract}
In this study, an unbalanced and practical European low-voltage micro-grid benchmark system is modelled and proposed for the sake of power system frequency studies. The model is adapted from Cigre Benchmark model to integrate Distributed Energy Resources (DERs). As the benchmark system is obtained from the real network, it will enable industrial and academic researchers to do a wide range of sensitivity analyses and design a flexible microgrid for future power system studies. The suitable dynamic modellings of two gas turbines, two battery units, two wind turbines and four photovoltaic panels are selected and appended into the proposed microgrid system. Moreover, the system contains customer loads which are divided into residential and commercial demands. The photovoltaic (PV) units have a total power of $210 \mathrm{kVA}$. Two wind turbines are Type 4 direct drive permanent magnet synchronous generator and nominal apparent power of each of them is $500 \mathrm{kVA}$. The batteries are respectively rated to $35 \mathrm{kVA}$ and $25 \mathrm{kVA}$ at 0.85 power factor (lagging). The model is stimulated using DIgSILENT Power Factory software. Time domain simulation results in terms of DERs' power outputs, frequency response and Rate of Change of Frequency (RoCoF) following a load event and under discrepant renewable energy penetration levels and inertia amounts are deployed to validate the flexibility of the test system proposed.
\end{abstract}

Keywords-Distributed energy sources; Inertia, Microgrids; Rate of change of frequency, Renewable energy integration

\section{INTRODUCTION}

Rapid employment and penetration of renewable energy sources (RESs) in microgrids have decreased the system inertia since they are connected through the converters [1]. A microgrid system can be subjected to the large excursions of frequency in case of low inertia level. Thus, the frequency stability of the system depends on the inertia or kinetic energy of rotating machines connected to the power system. Inertia is highly important to preserve the stability of the power system [2]-[3].

It is to be noticed that following an unexpected loss of generation or load change, a loss of synchronism between the generation and load may result in a partial or entire micro-grid islanding [4], [5]. To avoid this disaster, time-domain simulations, frequency nadir and Rate of Change of Frequency (RoCoF) evaluation should be investigated offline. In other hand, the parameters and types of all devices' dynamic modelling should be available for running system dynamic analysis. In this context, a few test systems for microgrids are proposed which are not practical enough [6]-[12]. Moreover, there are several cases those the dynamic models of all equipment should be selected by researchers which lead to contradiction.

As studies of Distributed Energy Source (DER) based models are gaining interest, a single benchmark model will not represent all types of microgrid. In the literature, many benchmark models have been presented, changing according to technologic developments [4]-[6]. A radial distribution test system is presented in [7] for North Africa. In [8], a benchmark system is provided only for power system static analysis. The concept of AC Low Voltage (LV) distribution systems is designed in [9] where a DC connection is considered for the customers to adjust the supply voltage through the power electronics.

In order to tackle with the above noticed issues, a realistic dynamic test system including Distributed Energy Resources (DERs) such as Photovoltaics (PVs), Wind Turbines (WTs) and Battery Energy Storage Systems (BESSs) are modeled in this study. The main advantages of the selected benchmark are established by CIGRE Task Force (TF) C6.04.02, in a communal base in the newest form of benchmark system for integration of DERs [10]. This test system is deployed in this paper and several DERs are integrated into it. System dynamic analysis is also provided under increment of the penetration levels of RESs in the grid.

The benchmark network consist of 37 nodes with the combination of residential, industrial and commercial subnetworks, including 6 residential, 8 commercial loads and one industrial load connected by underground and overhead line topologies [10]. This benchmark system provides a high variety of testing for integration of DERs into the system. In [10], there is also a medium voltage grid designed for the proposed European LV system which can be added to be as a upstream network for further studies. The proposed network can be a good candidate for testing discrepant solutions in the areas of microgrids in terms of power system frequency, stability, dynamics and smart grid methods. The test system provided in DIgSILENT Power Factory [11] can be straightforwardly transferred into other software package such as RSCAD, PSCC, PSCAD and etc.

\section{MODELLING REQUIREMENTS}

\section{A. Selecting the Test System \& European Grid Data}

The test system used in this report are modelled based on the Cigre`s "Benchmark Systems for Network Integration of Renewable and Distributed Energy Resources" document [10]. The integration of distributed energy resources (DER) are being investigated by many academic and industrial institutes for more practical investigations. 
TABLE I. PARAMETERS OF EUROPEAN GRID EQUIVALENT OF RESOURCE-SIDE BENCHMARK

\begin{tabular}{|c|c|c|c|}
\hline \multirow{2}{*}{$\begin{array}{l}\text { Voltage } \\
\text { level }\end{array}$} & \multicolumn{3}{|c|}{$\begin{array}{l}\text { Parameters of European grid equivalent of resource-side } \\
\text { benchmark }\end{array}$} \\
\hline & $\begin{array}{l}\text { Grid voltage, Vo } \\
{[\mathrm{kV}, \mathrm{rms} L L]}\end{array}$ & $\begin{array}{lr}\text { Short } & \text { circuit } \\
\text { power, } & \text { Ssc } \\
{[M V A]} & \end{array}$ & R/X Ratio \\
\hline $\begin{array}{l}\text { Low } \\
\text { voltage }\end{array}$ & 0.4 & 1 to 10 & 0.70 to 11.00 \\
\hline $\begin{array}{l}\text { Medium } \\
\text { voltage }\end{array}$ & 20 & 100 to 1000 & 0.40 to 2.00 \\
\hline $\begin{array}{l}\text { High } \\
\text { voltage }\end{array}$ & 220 & 5000 to 20000 & 0.07 to 0.60 \\
\hline
\end{tabular}

This benchmark system is selected to test power system distribution networks in order to facilitate the stimulation based analysis and validate the developed methods and techniques.

DIgSILENT Power Factory software is deployed to design the European low voltage (LV) microgrid model. The system comprises a variety of distributed generators (DGs), distributed storage (DS) and customer loads as residential and commercial loads. The software is especially for electrical power systems and enables advanced analysis of transmission, distribution and industrial system with faster result ability.

The European grid has an equivalent $50 \mathrm{~Hz}$ system frequency. The grid voltage levels are the European low, medium and high voltage levels assumed in the network, given in Table 1. In the proposed system the short circuit current is selected as 10000 MVA for HV level and 110 MVA for the MV level, and the $\mathrm{R} / \mathrm{X}$ ratios are selected 0.1 and 1 respectively, to better observe the change of DERs on system voltage.

\section{B. Dynamic Modeling of a Power System}

The fundamentals of dynamic simulation depend on the inertia. Inertia of the system can be defined as a force that opposes any changes might occur in frequency [12]. Low inertia issues are starting to be considered due to the increase in the penetration level of renewable energy sources (RES) in the power system, which is not contributing to system inertia. The RES are connected to the grid with power electronic (PE) interfaces which decouple the inertia from the main grid.

The equation (1) is the swing equation, where $\mathrm{df} / \mathrm{dt}$ is the rate of frequency change of frequency, $\mathrm{H}$ is the system inertia constant, $\mathrm{SB}$ is the generator rating power, $\mathrm{Pm}, \mathrm{Pe}$ are the mechanical power and electrical power, and $\mathrm{f} 0$ is the system frequency [13].

$\frac{d f}{d t}=\frac{f_{0}}{2 H S_{B}}\left(P_{m}-P_{e}\right)$

Figure 1 shows the frequency response of the system for different inertia constants. According to Figure1, rate of change of frequency (RoCoF) is inversely proportional to system inertia. As the power system inertia decreases, the frequency nadir, where the RoCoF reduces to zero, will be deeper and the time where the frequency nadir happens will be earlier.

\section{NETWORK MODEL CONFIGURATIONS}

The LV distribution benchmark is obtained from a real LV network, enabling flexibility in the DERs integration cases. The benchmark consists of three feeders that are residential, industrial and commercial based, correspondingly.

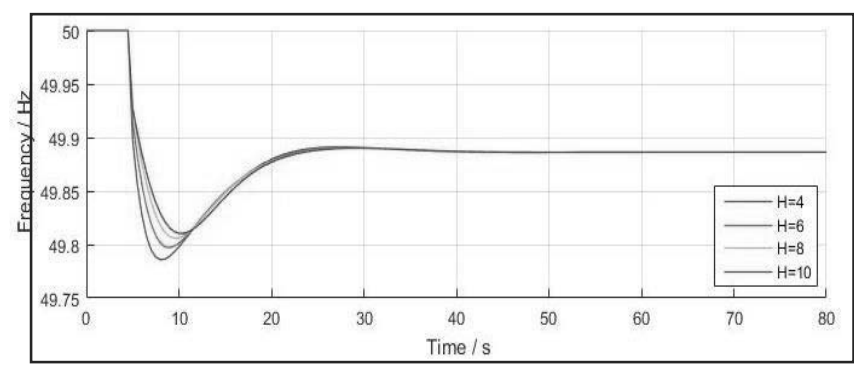

Fig 1. The Effect of Inertia Constant on Frequency Response

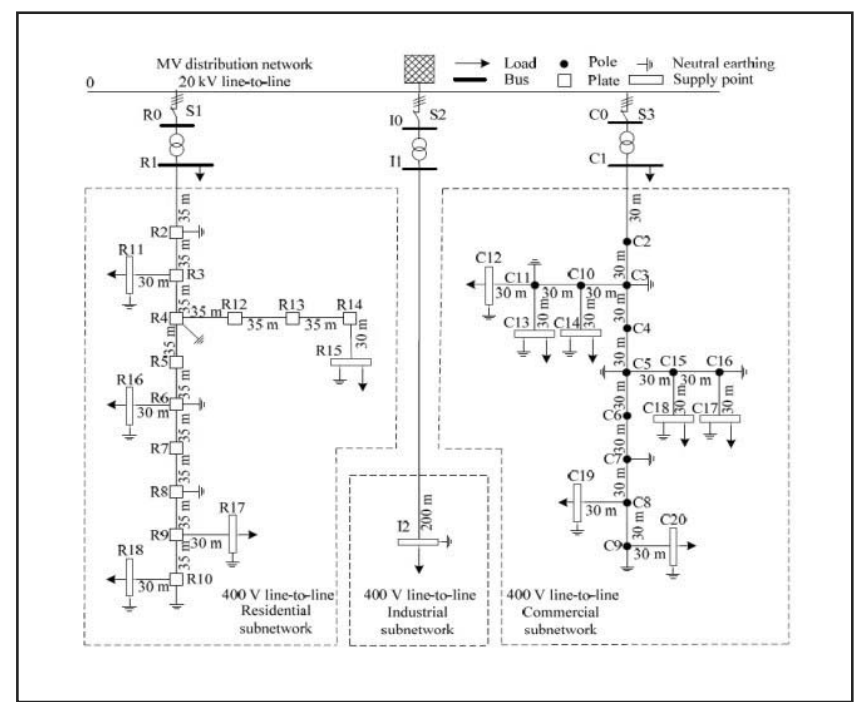

Fig 2. Topology of European LV distribution network benchmark [10]

Structure: The LV distribution networks have a radial layout and originate from a MV/ LV substation. The LV distribution network may include one or multiple lines. The system frequency is $50 \mathrm{~Hz}$.

Symmetry: The connection of single-phase consumers makes LV networks inherently unbalanced. In addition, single-phase lines may exist, particularly as feeder branches.

Line types: LV network lines can be underground, mainly located in urban areas with a high load density, or overhead as mainly located in rural areas with a fairly low load density.

\section{A. Selecting Parameters}

LV distribution is firstly selected to integrate DER to see the effect of renewable sources in a smaller scale system. In this test system, firstly a low-voltage (LV) distribution microgrid system is presented. The main difference of a microgrid from distribution network is the consideration of DERs and BESSs in microgrid. The location of the DERs and BESSs are selected according to sensitivity analysis to provide system reliability and cost minimization. According to these considerations the LV distribution network is converted to microgrid. The $20 \mathrm{kV}$ (MV) upstream network is converted to $0.4 \mathrm{kV}$ (LV) by 0.5 MVA rated power and 20/0.4 kV rated voltage transformer. There are four transformers in the modified system; one extra transformer is added to the benchmark model, which connects an extra wind turbine to the system selected according to sensitivity analysis. The lines are modelled in two topology i.e. overhead and underground lines. The loads are in three models including of residential; industrial and commercial loads. The bus/plate/pole representations are made as residential buses/plates from R0 to $\mathrm{R} 18$, industrial buses as I0, I1, I2 and commercial buses/ poles from $\mathrm{C} 0$ to $\mathrm{C} 20$. The DERs and loads are connected to the transformers to the MV distribution network through switches $\mathrm{S} 1, \mathrm{~S} 2$ and $\mathrm{S} 3$ to test configurations under different circumstances. Figure2 shows the topology of LV model. 


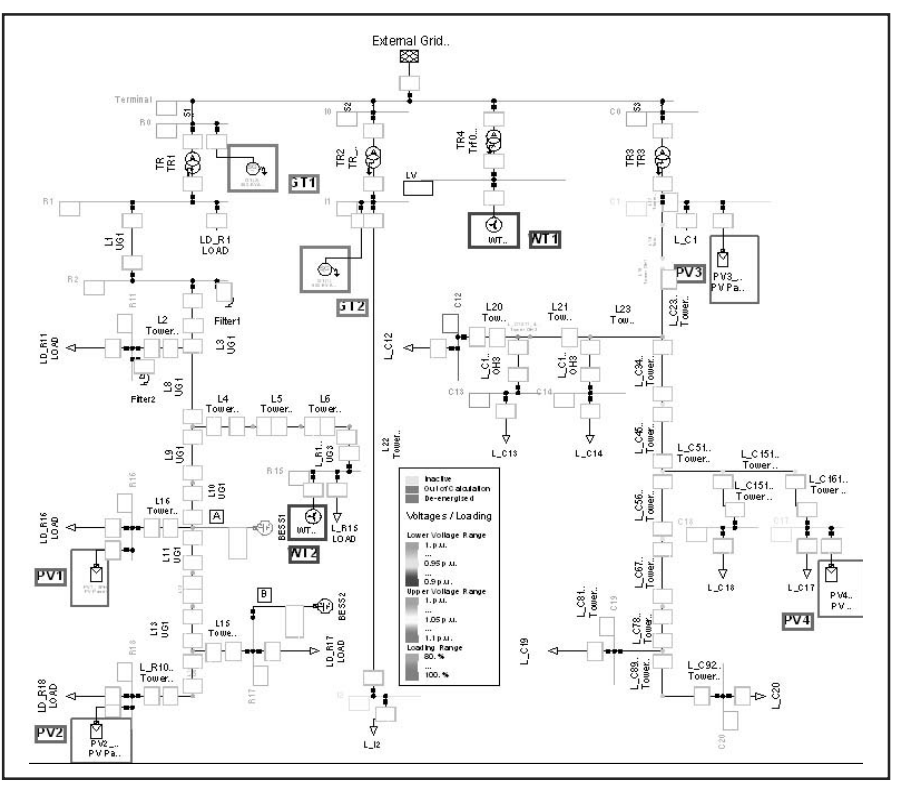

Fig 3. Locations of DERs and GTs in modelled LV distribution system (DIgSILENT): The blue, red and green colors respectively show WTs, GTs and PVs.

\section{A. Simulations}

DIgSILENT Power Factory is widespread used power system analysis software, particularly in Europe. The main customers constitute of academic research institutes, universities; transmission and distribution system operators.

Figure 3 shows the modelled LV distribution system in DIgSILENT software. The diagram colors show the loading ranges of the system. The squares drawn with red color shows the gas turbines, the circles drawn with blue color shows the wind turbines and the rectangles drawn with green color shows the photovoltaic panels in the system. There is an additional transformer compared to the benchmark model, connecting WT2 to the microgrid, which is selected according to the sensitivity analysis.

\section{B. The installation of the DERs}

As a case study, two gas turbine units, two battery units, two wind turbines and four photovoltaic panels are appended into the proposed microgrid system. Two gas turbines are also added to support a faster frequency response. GT1 is rated at $500 \mathrm{kVA}$ and GT2 is rated at $350 \mathrm{kVA}$ nominal apparent power. The batteries are used to provide frequency regulation during the isolated operation. These units are chosen according to the benchmark system introduced in [10], where DC-AC inverters are respectively rated to $35 \mathrm{kVA}$ and 25 $\mathrm{kVA}$ at 0.85 power factor lagging. The inverters are controlled with P-f and Q-V droops in order to share the network load. The photovoltaic (PV) units are selected as 50 and $55 \mathrm{kVA}$ nominal apparent power. Active power dispatches are altering of the PVs and they are connected at different nodes with a total power of $210 \mathrm{kVA}$.

Fully rated converter based wind turbines with $500 \mathrm{kVA}$ nominal apparent power with a power factor of 0.9. Each wind turbine is connected to the grid via converter infrastructure.

1) BESS: The simple battery model is created in DIgSILENT Simulation Language (DSL). The input of the system is $D C_{\text {in }}$ voltage, where output of the system is the $D C_{\text {out }}$ voltage, the SOC and $D C_{\text {cell }}$ voltage.

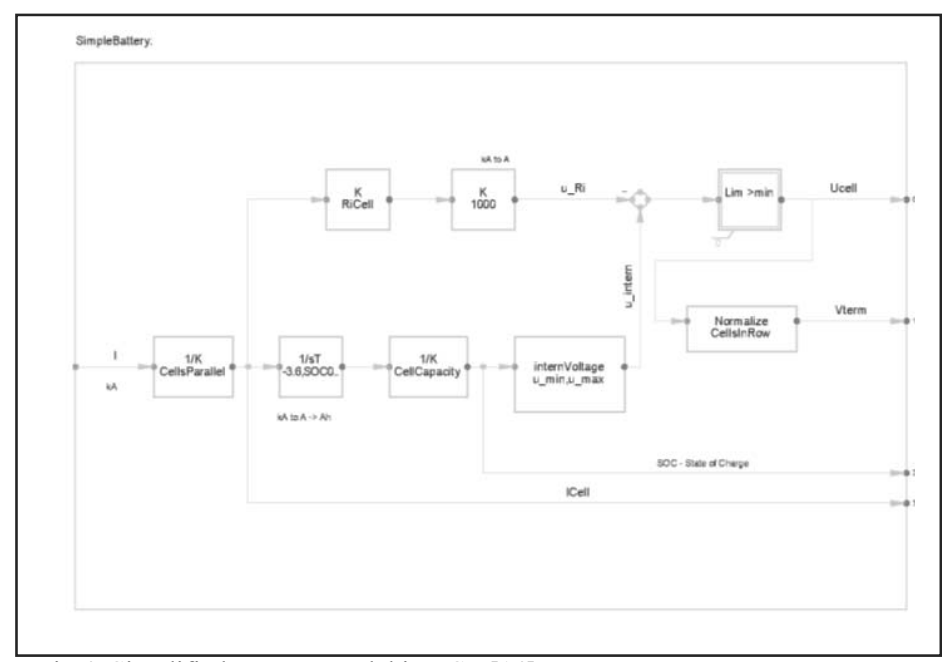

Fig 4. Simplified Battery Model in DSL [14]

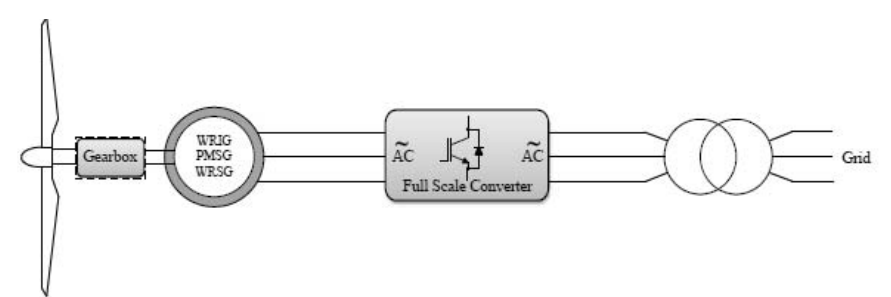

Fig. 5.Full Scale Converter Wind Turbine (Type 4)

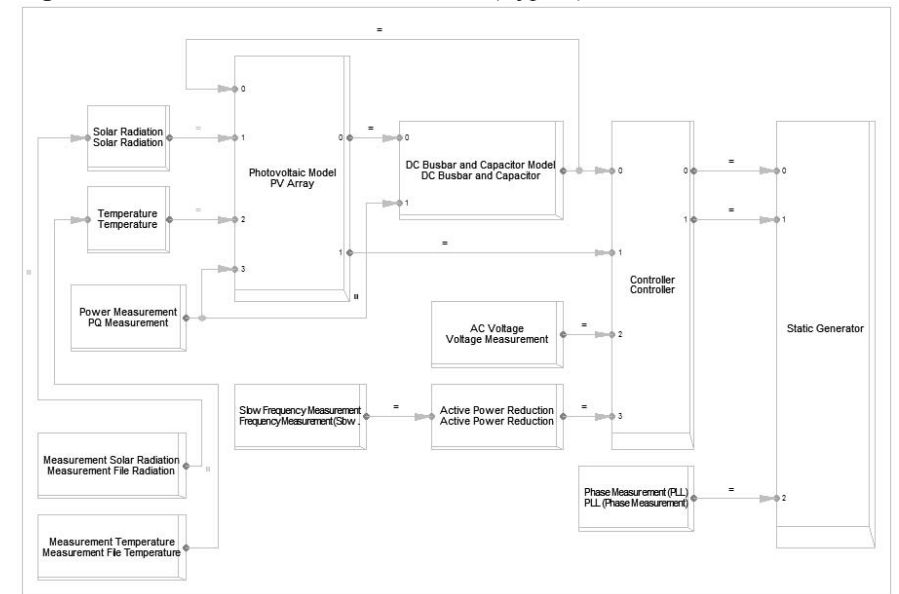

Fig. 6. Frame PV System [17]

The integrator shown with $1 / \mathrm{sT}$ has the state variable of SOC, applied here with the initial condition SOC0. During the initialization the battery is not charging/ discharging. For the load flow calculations active power exchange is zero. Figure 4 shows the simplified battery model in DSL.

2) Wind Turbine Model: The proposed study uses the IEC 61400-27-1 wind turbine generator (WTG) model in the DIgSILENT software. The models are described in [15]. The WTGs are considered in four different types, explained in detail below. Figure 5 shows the Type 4 wind turbine model.

The turbine is designed for low/moderate wind speed areas. The specifications of the wind turbine are entered into the Static generator wind turbine model in DIgSILENT. The nominal apparent power is defined as $0.5 \mathrm{MVA}$ and power factor as 0.9. The other details can be found in [16].

The fully rated WTG is in the single line diagram represented by a static generator. In this model, a $0.5 \mathrm{MW}$ turbine was designed and studied. 


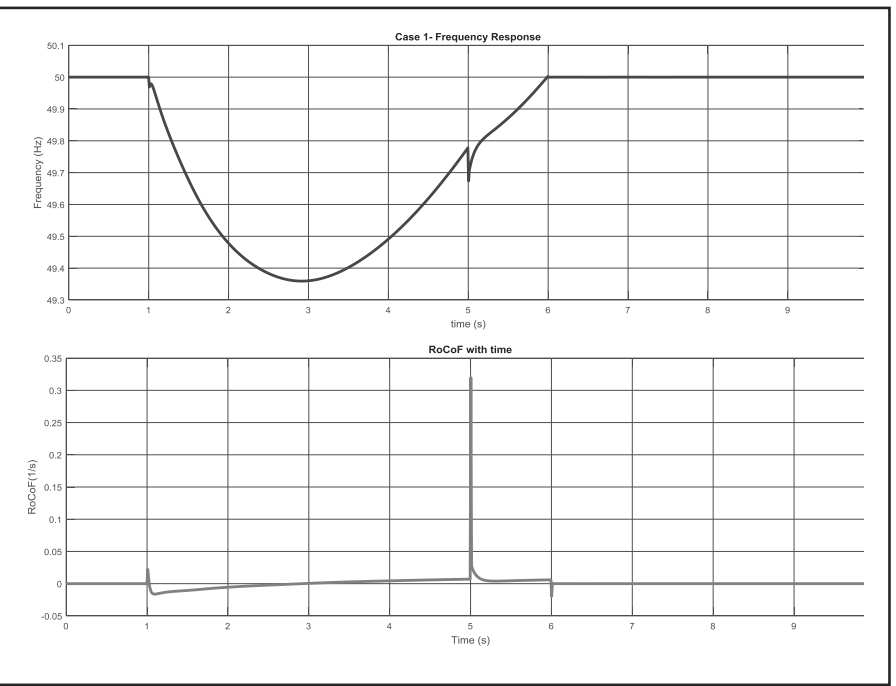

Fig. 7. Case 1 Frequency Response \& RoCoF

Input parameters of the wind turbine block are generator speed, wing angle and wind speed. At the exit of the block, the mechanical torque unit value (p.u.) is given as input to PMSG. A, B, C ends of the PMSG are in bi-directional interaction with the network. The PMSG voltage is transmitted to the network via an inverter designed with uncontrolled rectifier and MOSFETs.

3) PV Model: The Photovoltaic System (PV) element in DIgSILENT is based on the Static Generator. The PV System model consists of an array of PV panels, connected to the grid through a single inverter. In addition to the static generator is that the PV System automatically estimates the active power setpoint, for the provided geographical location, date and time.

Figure 6 gives the frame of the PV system in DIgSILENT. The inverter in the system is modelled as a static generator, enabling active power calculations. The PV cell is modelled using DSL, receiving data from solar radiation and temperature modules. The DC busbar and capacitor module is also modelled by DSL, having an input from PV module and power measurement module. The controller has inputs from DC busbar and capacitor module, PV module, AC Voltage measurement module and active power reduction module. The controller gives id_ref and iq_ref outputs to the inverter. PLL also gives the reference voltage angles to the inverter module.

\section{DYNAMIC SIMULATIONS}

A. Base case system response without DGs/Storages (Case1) The base system response without all DGs and storage systems is observed with a scenario of disturbance at $5 \mathrm{~s}$. Two gas turbines are installed to support frequency in the system. The external grid is apart from the system at $\mathrm{t}=1$ and connected back to the system at $\mathrm{t}=6 \mathrm{~s}$. Figure 7 shows the frequency response and RoCoF of the system at Case 1. The active power performance of the system is firstly tested from load flow analysis when the microgrid is working in islanded operation. In the islanded operation, the generation $(703.86 \mathrm{~kW})$ meets the load demand $(686.55 \mathrm{~kW})$ with the grid losses $(17.36 \mathrm{~kW})$. After verifying the isolated operation, when the microgrid is in islanded mode from $1 \mathrm{~s}$ to $6 \mathrm{~s}$, it is capable of providing the power balance.

\section{B. Base case system response with all DGs without Storages} (Case2)

In this case, the effect of the converter based renewable energy generation systems are investigated.

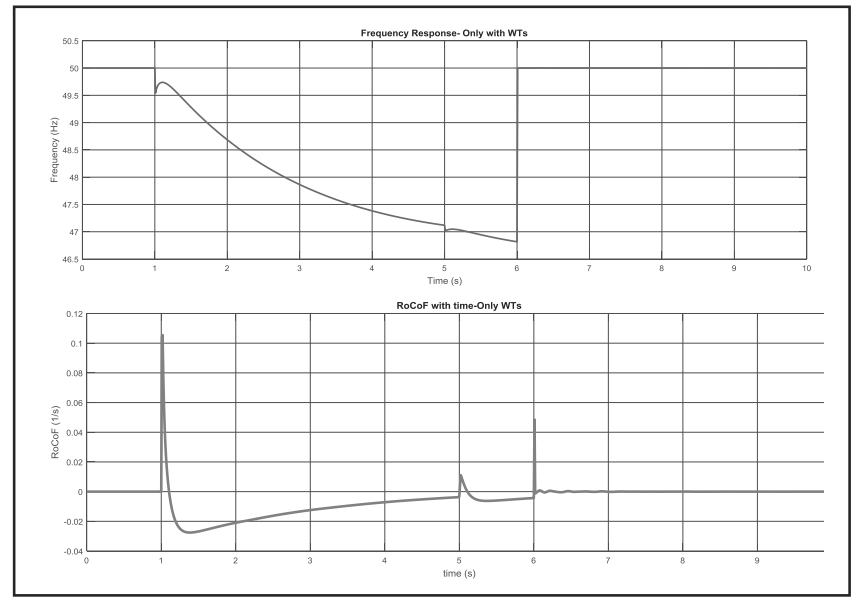

Figure 8 . Case 2 Frequency Response \& RoCoF only with WTs

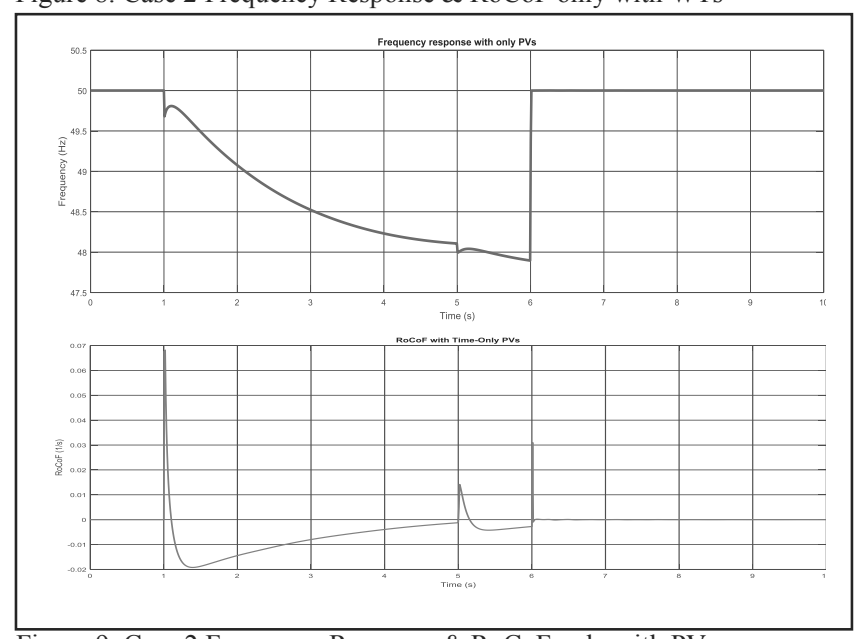

Figure 9. Case 2 Frequency Response \& RoCoF only with PVs

It is known with the integration of renewables to the network, there is no contribution to the inertia of the system. This leads to a selective integration of the renewables. In this study, a step by step approach is followed to see the effect of each DG on the system. Firstly the contributions of the WTs are examined and later the PVs are integrated. The same scenario steps in Case 1 are repeated as shown.

a) Only with WTs: The system includes only the two WTs as a renewable source. As seen in Figure 8, the frequency drop exceeds the permitted frequency level by $3 \mathrm{~Hz}$ (the permitted frequency nadir is $46.7 \mathrm{~Hz}$ ) and it's not possible to connect to the real existing grid. Also in Figure 8, the RoCoF increases sharply in $\mathrm{t}=1 \mathrm{~s}$ which is considered a high value in the case of frequency dynamics.

b) Only with PVs: Another situation is only with the PVs in the system without storage and WTs. In Figure 9, the frequency response is shown. Here the frequency nadir is around $48 \mathrm{~Hz}$, which is better compared to the previous system with only the WTs, but it is still not enough for the stable connection to the grid. Similarly in Figure 9 the maximum RoCoF value is less than the previous simulation, almost $0.071 / \mathrm{s}$.

c) With WTs and PVs: After analyzing the simulation results for only WT integration and only PV integration, the system is stimulated with both WTs and PVs in the system. Figure 10 shows the frequency response of the overall system. 


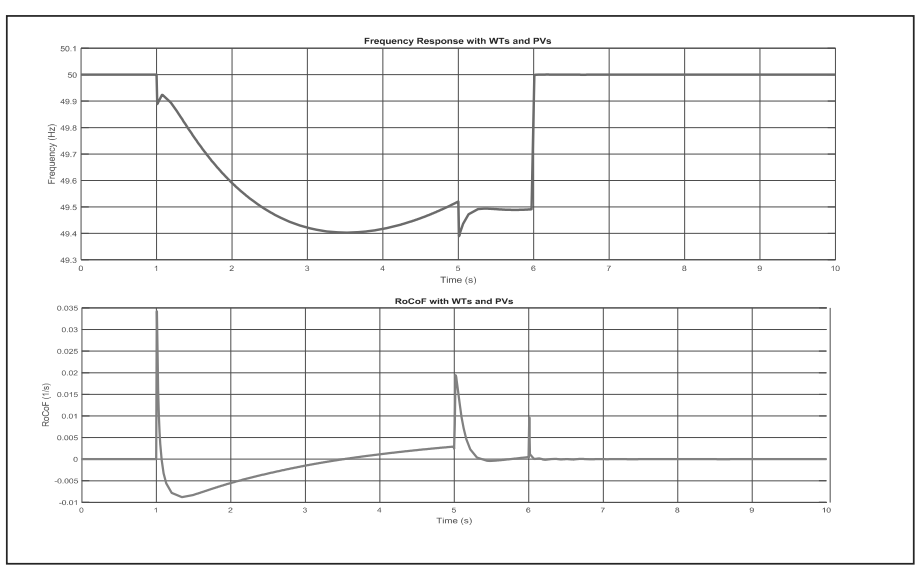

Figure 10. Case 2 Frequency Response \& RoCoF with WTs and PVs

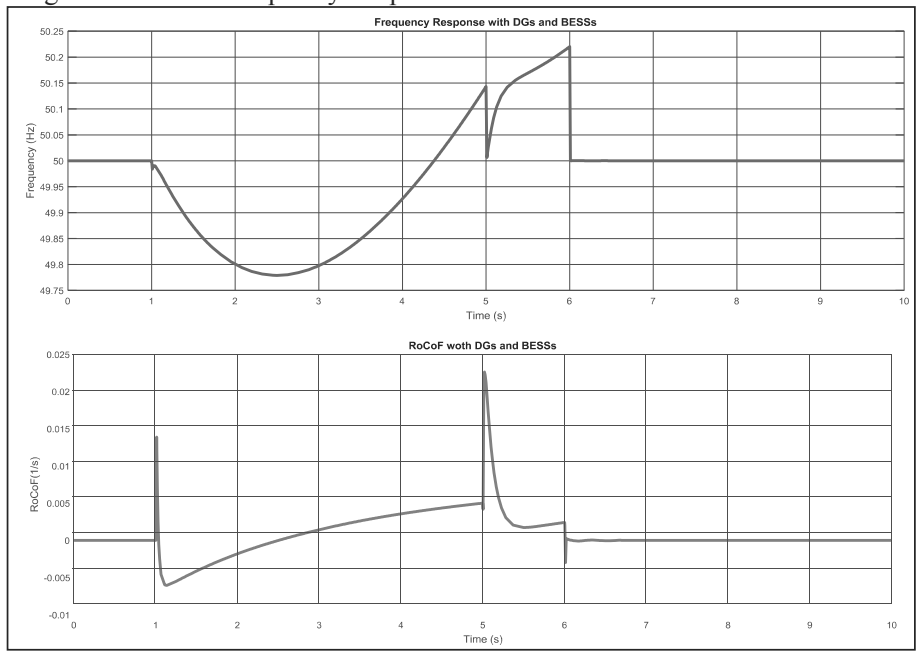

Figure 11. Base case system response with all DGs, with storages

After the simulations are run, in the first second frequency is stable with the support of the external grid. When the switch is opened at $\mathrm{t}=1$, the frequency begins to drop as a fact of disconnection from the external grid. The frequency dropped down until 49.4, which is the frequency nadir. With the integration of the WTs and PVs, the system frequency drop is less and at $\mathrm{t}=3.7 \mathrm{~s}$, the system starts to back up from the frequency nadir.

\section{Base case system response with all DGs, with storages}

In this case, the effect of the converter based renewable energy generation systems and storage systems are investigated. By using Case 2, the batteries are added to the system as shown in Figure 10. The placement is made at points $\mathrm{A}$ and $\mathrm{B}$, which line has the most load density and the BESSs are aimed to contribute to the frequency stability. The same scenario steps in Case $1 \&$ Case 2 are repeated as shown in figures.

Figure 11 shows the frequency response of the system. After the simulations are run, in the first second frequency is stable with the support of the external grid. When the switch is opened at $\mathrm{t}=1$, the frequency begins to drop. The frequency dropped down until 49.78, which is very improved compared to previous cases. With the contribution of two BESSs, at $\mathrm{t}=2.5 \mathrm{~s}$, the system starts to back up from the nadir.

\section{CONCLUSIONS}

In this paper, the unbalanced European test system is modelled in DIgSILENT PowerFactory and its dynamic performance is investigated following the load increment. The appropriate dynamic models of gas turbines, BESSs, WTs, and PVs for the sake of power system frequency studies are selected and evaluated under different RES penetration levels and islanding mode.

One of the main aims of the study done is to reveal the importance of a practical microgrid system to meet the needs of the researchers for power system dynamic analysis. As a conclusion of the simulations, WTs and PVs aggravate the frequency regulation; however, the GTs and BESSs deployment can appropriately regulate the system frequency without causing a massive frequency drop. Additionally, the ratings of BESSs and GTs are arranged in the simulation cases to improvise the frequency stability. It is to be pointed out that the BESSs are the most beneficial solutions to help frequency restoration found in this work. As a future research, loads can also be modelled dynamically and the controllers can be designed for the frequency service providers to help the frequency restoration process.

\section{REFERENCES}

[1] REN21, "Renewables 2017 global status report,"2017.

[2] P. G. G. P. Nieto, David Egido, "Contribution of Aggregated Distributed Energy Resources In Primary Frequency Control,” 2017.

[3] P. Tielens and D. van Hertem, "Grid Inertia and Frequency Control in Power Systems with High Penetration of Renewables," Status Publ., vol. 0, no. 2, pp. 1-6,2012.

[4] K. Strunz, R. H. Fletcher, R. Campbell, and F. Gao, "Developing benchmark models for low-voltage distribution feeders," 2009 IEEE Power Energy Soc. Gen. Meet. PES '09, no. July, pp. 1-3,2009.

[5] K. Strunz, "CIGRE Task Force C6 . 04 . 02: Developing Benchmark Models," Symp. A Q. J. Mod. Foreign Lit., vol. 6, no. Coll, pp. 4-5, 2005.

[6] N. A. Vovos, "The CIGRE HVDC benchmark model - A new proposal with revised parameters," Electra CIGRE's Biling. Bimon. J. Power Syst. Prof., no. December, 1994.

[7] IEEE Distribution Planning Working Group, "Report: Radial distribution test feeders," IEEE Trans. Power Syst., vol. 6, no. 3, pp. 975-985, 1991.

[8] IEEE, IEEE Recommended Practice for Industrial and Commercial Power Systems Analysis. 1998.

[9] J. Dickert, G. Seth, and P. Schegner, "Comparison of design concepts for AC low voltage distribution networks," 2014 IEEE PES Gen. Meet. | Conf. Expo., pp. 1-5,2014.

[10] CIGRE, Benchmark Systems for Network Integration of Renewable and Distributed Energy Resources, no. April.2014.

[11] D. PowerFactory, "No Title," 2017. [Online]. Available: http://www.digsilent.de/.

[12] P. Kundur et al., "Definition and Classification of Power System Stability IEEE/CIGRE Joint Task Force on Stability Terms and 
Definitions," IEEE Trans. Power Syst., vol. 19, no. 3, pp. 1387$1401,2004$.

[13] P. Kundur, N. J. Balu, and M. G. Lauby, Power System Stability andControl. McGraw-Hill Education, 1994.

[14] D. Gmbh, "DIgSILENT PowerFactory Application Guide Battery Energy Storing System Template,” p. 28,2010.

[15] "IEC 61400-27-1 Electrical Simulation Models for Wind Power Generation.”2015.
[16] EWT, "High Yield 500kW Direct Drive Wind Turbine," 2013 [Online].Available:http://www.ewtdirectwind.com/uploads/media/L eaflet.EWT500kW. pdf. [Accessed: 01-Sep-2017].

[17] DIgSILENT, "Documentation Photovoltaic System Template," PowerFactory 2017, 2017. 